\title{
Pollination Ecology of Cypripedium reginae Walter (Orchidaceae): Size Matters
}

\section{Retha Edens-Meier ${ }^{1}$, Mike Arduser ${ }^{2}$, Eric Westhus ${ }^{3}$ and Peter Bernhardt ${ }^{4}$}

\author{
${ }^{1}$ Department of Educational Studies, Saint Louis University, St. Louis, MO, USA 63103 \\ ${ }^{2}$ Missouri Department of Conservation, St. Louis, MO, USA 63304 \\ ${ }^{3,4}$ Dept. of Biology, Saint Louis University, St. Louis, MO, USA 63103
}

\begin{abstract}
As in most pollinator-limited orchids lacking edible rewards, a population of C. reginae in southern Missouri showed a low conversion ratio of flowers into fruits $(0.046-0.23)$ over two seasons. There was no relationship between the length of the secondary flowering stem, the number of foliage leaves on the same stem and the number of flowers (one or two) produced at the terminus of the stem. However, the size mattered based on the physical dimensions of pollinia-carrying insects vs. parameters of floral architecture. While a diverse range of floral visitors (Coleoptera, Diptera and Hymenoptera) to C. reginae were observed over three seasons, only six medium-sized bees (Anthophora, Apis and Megachile spp.) carried segments of massulate pollinia after three seasons of observation and collection. Pollinia were always deposited dorsally on the thorax. These bees had a mean width of $4.44 \mathrm{~mm}$ and depth of $3.41 \mathrm{~mm}$ whereas the rear exit length and width of the orchid measured $6.53 \mathrm{~mm}$ and $3.41 \mathrm{~mm}$. respectively. In contrast, the more numerous but smaller bees $(2.66 \mathrm{~mm}$ width and $2.16 \mathrm{~mm}$ depth) in the genera Augochlorella, Augochlora, Ceratina, Lasioglossum spp. etc., exited the flower via the same rear orifices without pressing against the dehiscent anthers. Larger bees (gynes of Bombus spp.) measuring $9.06 \mathrm{~mm}$ in width and $6.25 \mathrm{~mm}$ in depth, were too large to escape via the rear exits so they left the flower via the large, dorsal entrance (through which they first entered the labellum) never contacting either anther. As in the small-flowered C. plectrochilum, the larger flowered C. reginae receives many floral visitors but selects for pollinia-vectors of a discrete body size.
\end{abstract}

\section{Introduction}

The conversion rate of flowers into fruits containing viable seeds is notoriously low in the majority of orchid species that are obligate out-crossers but offer no rewards (Tremblay et al. 2005). Because the majority of orchid species offer no edible rewards and fruit set is so low, population fecundity remains an ongoing problem in orchid conservation regardless of geography. While many of these taxa are self-compatible, not all species self-pollinate (autogamy) in the absence of pollinators (Dafni \& Bernhardt 1989, Tremblay et al. 2005). For example, a review of the literature shows 
that mechanical self-pollination is rare in the genus Cypripedium L. (Bernhardt \& Edens-Meier 2010), although all species tested so far are self-compatible (Edens-Meier et al. 2010).

Bernhardt and Edens-Meier (2010) compared known pollinators and known fruit set in 15 out of the known 47 species in Cypripedium (sensu Cribb 1999). They noted that, while pollinators may vary between species, fruit set ratios often vary broadly within the same species according to population size, distribution, season, and local environmental conditions. For example, the percentage conversion of flowers into fruits in discrete populations of C. calceolus through Eurasia varies considerably. Fruit set in the same population in Byelorussia varies between 0.33-0.57 in different years (Stavrovskaja 1984 in Kull 2008) and in Sweden from 0-0.25 (Nilsson 1979 in Kull 2008). Why is there such a broad variation?

One reason is that pollination of Cypripedium spp. usually depends on a comparatively narrow range of pollinators with restricted physical dimensions. There is an optimal size for insect pollinators in relation to floral architecture regardless of the diversity of anthophilous insects attracted by more generalist colour patterns and fragrances (Banziger et al. 2005, 2008; Li et al. 2006, 2008). The "goodness of fit" between the insect's body and the interior dimensions of the Cypripedium flower governs whether or not the insect carries pollen masses as it exits the rear orifices of the flower and those same masses contact receptive, stigmatic papillae when it enters a second flower of the same species. Consequently, when bumblebee (Bombus) queens (gynes) fail to visit flowers of $C$. acaule at two sites in North America the conversion ratio of flowers into fruit may drop from 0.25 to 0.0 (Bernhardt \& Edens-Meier 2010).

However, the frequency and diversity of insect visitors to flowers of Cypripedium spp. shows two intergrading trends. In some species, e.g. C. acaule (Stoutamire 1967), C. bardolphianum (Zheng et al., in press), C. fasciculatum (Ferguson \& Donham 1999) and C. tibeticum ( $\mathrm{Li}$ et al. 2006), observers report that flowers are visited exclusively by their pollinators although such visitations may be infrequent to rare. In contrast, observations and collections of floral foragers to C. plectrochilum (Li et al. 2008), C. guttatum (Banziger et al. 2005) and, to a lesser extent, C. yunnanense and C. flavum (Banziger et al. 2008) show that these flowers have a wider variety of floral visitors representing multiple species in three insect Orders. The physical dimensions of most of these generalist foragers are either too large to enter the inflated labellum or too small or narrow to contact the receptive stigma and/or the dehiscent anther as they exit the flower. The act of pollinia dispersal in C. plectrochilum, for example, remains relegated, as usual, to species within the one bee genus (Lasioglossum; Halictidae) all with overlapping physical dimensions.

We decided to re-examine the pollination mechanics, floral architecture and pollinator dimensions of $C$. reginae because the past three studies on this species offer contradictory results and did not provide flower pollinia vector measurements. This species has the third largest flower of all North American Cypripedium spp. (Luer 1975). An early study suggested that the dominant pollinator of populations of this species in Ontario, Canada were medium-large bees (see review in Van der Cingel 2001). In contrast, Vogt (1990) observed and collected small syrphid flies (Syrphus sp.), and even scarab beetles in the genus Trictiotinus, carrying pollen of the host flower at a second site in Vermont, U.S.A. Herring (2007) observed and collected insect visitors 
of C. reginae at two populations in two disjunct sites in southern Missouri, U.S.A., the southwestern limit of its range. At the Angeline site in southern Missouri, a solitary skipper butterfly (Polites sp.) and six bees ( $<7.5 \mathrm{~mm}$ in length) entered its flowers. The bees were identified as Ceratina calcarata (Apidae), Augochlora pura (Halictidae) and Augochlorella striata aurata(Halictidae). While all of these insects exited the flower through the rear orifices, as must all legitimate pollinators of all Cypripedium spp., none of Herring's insect specimens carried the host flower's pollen masses. This is especially interesting as Herring (2007) also studied the pollination ecology of another spring-flowering species, C. parviflorum var. pubescens in Missouri at three disjunct sites. Fragments of the massulate pollinia of $C$. parviflorum were definitely carried by five species of small, native bees including Ceratina calcarata and Augochlora pura.

Therefore, this paper attempts to resolve several interrelated questions regarding the pollination dynamics of $C$. reginae at th e Angeline site in southern Missouri. First, do taller and leafier stems make more flowers than shorter stems with fewer leaves? Second, which insects are most likely to carry its pollinia after visiting the flowers and do prospective pollinators share similar body sizes and are they closely related? Finally, is there a self-consistent parametric relationship between floral architecture and body size of insects carrying C. reginae pollinia?

\section{Materials and Methods}

Study Site and Annual Fruit Set. We used the same population in the Angeline Conservation Area (Lick Log Hollow), Shannon County, MO, as in Edens-Meier et al. (2010) for three seasons (2007-2009) during the last two weeks of May each year. We counted the number of flowering stems each May, the number of flowers/stem and then returned to the same site in mid-late summer to count the number of capsules. However, in 2008 Ms. Tamra Raven (pers. comm.) found that our population extended beyond the initial field site, adding an additional 45 flowers to the study in 2008 and 25 flowers in 2009. A voucher specimen of $C$. reginae in bloom was deposited in the Missouri Botanical Gardens herbarium (MO)(Bernhardt 6067487). We also made vouchers of Coreopsis lanceolata (Bernhardt 6067489) and Zizia aurea (Bernhardt 6067488 ) because their flowering periods overlapped with $C$. reginae and we noted that some insects visited the orchid and these other co-blooming plants.

Number of Flowers/Stem. Some stems of $C$. reginae produce only one terminal flower while others produced two. To determine whether there was a relationship between flower number and the physical robustness of the seasonal stem we counted the number of flowers/stem, the number of leaves/stem and the length of the stem (in $\mathrm{cm}$ ). A Welch t-test was used to compare the mean height of stems that produce one flower to the mean height of stems producing two flowers. A second Welch t-test was used to compare the mean number of leaves produced by stems with one flower to the mean number of leaves produced by stems with two flowers.

Assessment of Fruits/Stem. The natural rate of capsule production within the population was not recorded during 2007 because so many of the flowers within the population were manipulated in earlier hand pollination experiments (see EdensMeier et al. 2010). In 2008 and 2009 we counted the number of stems with flowers in May. We returned to the same site 8-16 weeks later to count the number of capsules on stems in the population. 
Floral Measurements. To determine the architecture of the flower vs. the size of prospective pollinators we used digital calipers to make the same measurements described by Li et al. (2006) for C. tibeticum, with one exception. We were not able to record the distance in millimetres of the receptive surface of the stigma to the base of the labellum sac as in Li et al. (2006) as this would have meant splitting labella open longitudinally and the Missouri Department of Conservation Regulations limited the number of flowers we could sample annually for breeding experiments (Edens-Meier et al. 2010).

Insect Observations, Collections and Measurements. Insects were observed in all three seasons for a total of approximately 180 hours. We usually arrived at the site by $9 \mathrm{AM}$ and left at $5 \mathrm{PM}$ after initial observations that there was no insect activity before or after these time periods. Inert/dead insect specimens were removed from labella, pinned and labeled for identification. We observed a) which insects approached flowers but did not enter, b) which insects entered the labellum through the large, dorsal orifice but then exited the flower via the same orifice and c) which insects entered the flower through the large, dorsal orifice but exited via one of the two, rear openings flanking each anther. Insects were collected with butterfly nets and euthanased in a jar with fumes of ethyl acetate. Specimens were pinned, labeled and identified but it was not possible to discern whether we collected Ceratina calcarata or C. dupla as the two species are separated by characters attributed to male specimens exclusively and we only collected females.

Three separate measurements were taken for each specimen with digital calipers:

1. Length from frons to tip of abdomen.

2. Width between the widest points on the insect's body. For most bees, this was the width of the segment at the base of the abdomen where it connects to the thorax.

3. Depth from the top to the bottom of the thorax.

Pollen Load Analyses. We used magnification visors to determine if the insect was carrying pollinia of $C$. reginae. Pollinia were removed with a probe and stained with Calberla's fluid (Bernhardt \& Dafni 2000). To determine whether the bee collected pollen on other species flowering within the same site each insect was placed on a glass slide and washed in two-four drops of ethyl acetate. The scopae and corbiculae of bees were scraped with a probe to dislodge additional loads or masses. After removing the insect from the glass slide and pinning the insect, the ethyl acetate was allowed to evaporate and then the residue was stained with drops of Calberla's fluid and mounted under a cover slip (Bernhardt \& Dafni 2000). The pollen slide was co-referenced with the same code used to identify the pinned insect specimen. The pollen of a particular plant species was counted as present on a slide if we counted in excess of 25 grains. However, the pollen of Cypripedium spp. is so distinct we also recorded whether insects carried trace amounts of this pollen defined here as $<10$ disconnected grains/slide. Co-blooming plants that provided pollen samples for the pollen reference library were pressed and deposited in MO. Insect specimens, measured and examined for pollen, were deposited in the American Museum of Natural History (Manhattan, New York). A series of Wilcoxon rank sum tests were used to compare the dimensions of insects where pollen was present to those where pollen was absent. The Wilcoxon rank sum test is a nonparametric test used to compare two samples (Sokal \& Rohlf 1995). It is equivalent to the Mann-Whitney test (Sokal \& Rohlf 1995), differing only in 
the procedure used to arrive at the test statistic. Wilcoxon tests were executed in the $\mathrm{R}$ statistical programming environment ( $\mathrm{R}$ Development Core Team, 2010) using the function "Wilcox.test" within the package, "stats." Wilcoxon tests were chosen over parametric methods due to the small number of insects found carrying pollen. Contrasts were set up as follows: three tests separately compared length, width, and depth measurements of insects where pollen was present to those where pollen was absent (excluding all specimens Bombus spp.), and a second round of three tests compared length, width, and depth measurements of insects where pollen was present to those of specimens in the genus Bombus. Some questions arose during the review process as to whether having multiple species with and without pollen influenced independence of the data. In this case, observations would have been dependent if the size of a visitor somehow directly influenced the size of a subsequent visitor. We have no reason to suspect that this was the case here.

\section{Results}

Relationship Between Stem Height, Leaf Number and Number Flowers/Stem. Measurements of the three characters are itemised in Table 1. We did not find a significant difference in mean stem height between stems with one and two flowers $(\mathrm{t}=0.8572, \mathrm{df}=26.199, \mathrm{p}=0.3991)$. Neither did we find a significant difference in the number of leaves produced by stems with one and two flowers $(t=0.4711, \mathrm{df}=29.975$, p-value $=0.641)$.

Floral Architecture and Presentation 2007-2009. Measurements of nine floral characters are summarised in Table 1. When the flower bud opens the labellum is resupinate on its pedicel and is usually held horizontally to the erect or leaning vegetative stem (Luer 1975, plate 8.1). The exterior of the labellum is glabrous and white with a broad pink blotch (Fig. 3; Luer 1975, plate 8.2). However, the interior of the labellum is marked by rows of deep pink-magenta spots and its base is lined with transparent, multicellular trichomes (Fig. 1). A large opening is located on the dorsal

\section{Table 1. Floral and stem measurements of Cypripedium reginae flowers}

$\begin{array}{lccc}\text { Measure } & \mathbf{n} & \text { Mean } & \text { SD } \\ \text { Ovary Length }(\mathrm{mm}) & 35 & 28.26 & 6.30 \\ \text { Column Length }(\mathrm{mm}) & 35 & 10.84 & 2.51 \\ \text { Labellum Length }(\mathrm{mm}) & 44 & 40.79 & 3.30 \\ \text { Labellum Width }(\mathrm{mm}) & 44 & 29.62 & 3.44 \\ \text { Entrance Length }(\mathrm{mm}) & 44 & 11.96 & 2.04 \\ \text { Entrance Width }(\mathrm{mm}) & 44 & 16.19 & 2.92 \\ \text { Entrance Depth }(\mathrm{mm}) & 44 & 24.98 & 3.28 \\ \text { Exit Length }(\mathrm{mm}) & 44 & 6.53 & 1.46 \\ \text { Exit Width (mm) } & 44 & 3.41 & 0.97 \\ \text { Plant Height }(\mathrm{cm}) & 35 & 67.87 & 14.71 \\ \text { Number of Leaves } & 35 & 7.11 & 1.16 \\ \text { Number of Flowers } & 35 & 1.37 & 0.49\end{array}$

T-tests comparing the number of flowers produced to height of plants $(t=0.8572, d f=26.199, p=0.3991)$ and the number of leaves $(t=0.4711, d f=29.975, p$-value $=0.641)$ fail to detect a relationship between the size of the plant and the number of flowers produced. 
surface of the labellum (Luer 1975). Two smaller dorsal openings are located to the rear of the labellum, flanking opposite sides of the staminode. Two lateral white petals are located on each side of the labellum. Two connate, white sepals hang underneath the labellum while a white dorsal sepal arches over the dorsal opening of the labellum, preventing the inflated pouch from filling with water when it rains. A white staminode with pink and yellow blotches covers the other organs that make up the column. The stigma is strategically positioned directly under the staminode while two anthers are located posterior and superior to the stigma. The flower emits a faint but pleasant floral fragrance, reminiscent of bluets (Houstonia).

Conversion of Flowers into Fruits 2008-2009. In 2008, only three out of 63 unmanipulated flowers (see Edens-Meier et al. 2010) produced mature capsules. In 2009, 13 capsules were produced from a total of 56 un-manipulated flowers. The conversion of flowers into fruit was $4.6 \%$ and $23 \%$ respectively.

\section{Comparative Behaviour and Identification of Floral Visitors}

Coleoptera. Four beetles were found in the labellum of four flowers in 2007. In all cases they remained in the labella throughout the day of observation and were never observed to exit the flower via the rear orifices. There were two Trichiotinus spp. (Scarabaeidae) and two specimens of Diabrotica undecimpunctata (Chrysomelidae). None carried pollen of the orchid or any other co-blooming plant. These species were also observed but not collected in labella in 2008 and 2009.

Diptera. A single calliphorid fly (Calliphoridae) was found dead in the labellum in 2007.

Lepidoptera. We observed, photographed, and filmed a variety of Lepidoptera (sphingid moths, butterflies and skippers, including the rare golden-banded skipper)

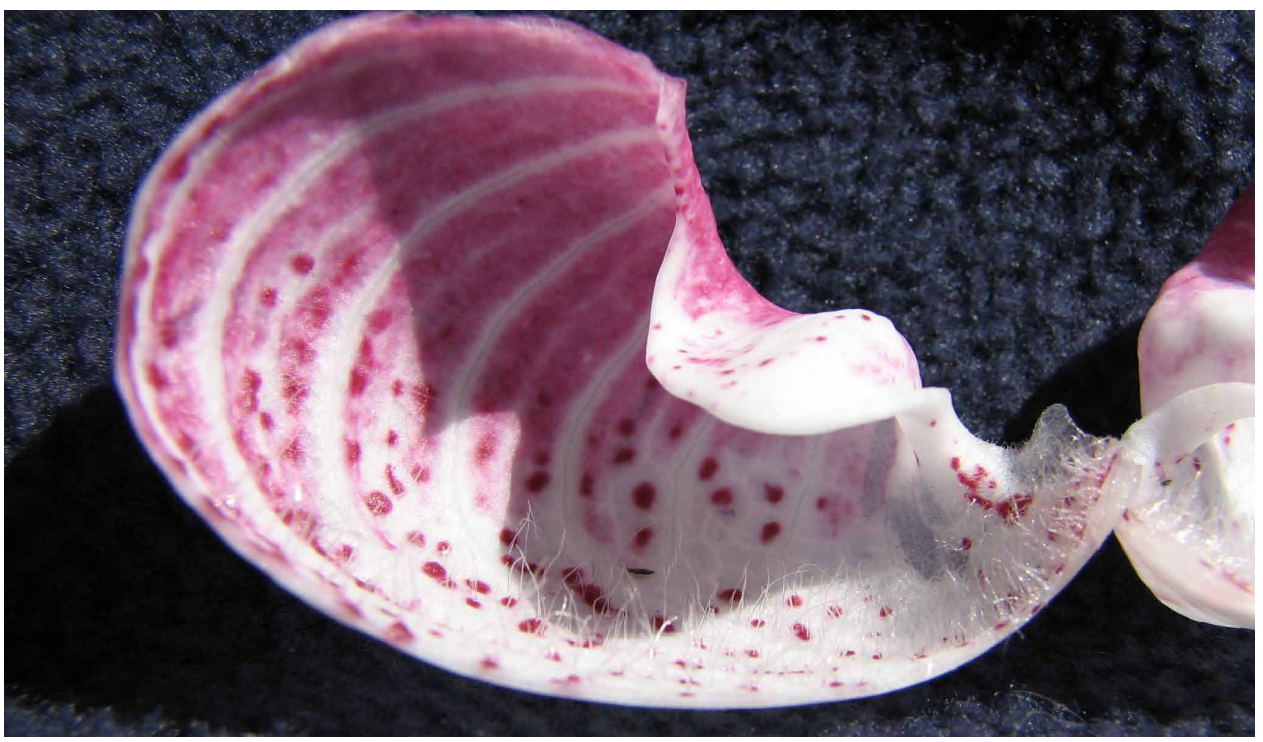

Fig. 1. Interior of labellum of Cypripedium reginae marked by rows of deep pink-magenta spots. The base is lined with clear multicellular trichomes. 
visiting flowers of C. reginae every season. Diurnal, unidentified, sphingid moths were observed and filmed, but not captured, as they hovered in front of the flower and then left the site without entering the labellum. We also observed and photographed the Great Spangled Fritillary (Speyeria cybele) as these large butterflies landed on the labella and extended their probosces onto the staminodes as well as the interior of the labellum. They appeared to be especially attracted to aging flowers with brown spots but were not observed to enter the labella (Fig. 2). Skippers (Rhopalocera) were the most common Lepidoptera on these orchids and included Polites spp., the golden banded skipper (Autochton cellus) and the Delaware skipper (Atrytone logan), These insects were observed flying from flower to flower of $C$. reginae. They extended their probosces, contacting the dorsal sepals, labellum entrances and staminodes (Fig. 3). They were especially common after rains and appeared to be drinking water droplets clinging to floral structures. When skippers entered the labella three things could occur. Some exited the labella through the same dorsal opening. Others remained in the labellum and died. In only one observation, a Polites sp. must have attempted to exit the labella by crawling under the stigma and out of the flower via one of the two exit canals. This exiting insect died en route with its head emerging from the exit orifice (Fig. 4).

Hymenoptera. Males of Xylocopa virginica were observed each season. We did not capture them because they hovered around the flowers without landing on them. Gynes in the genus Bombus (Apidae; Table 2) were observed each season and, on several occasions, engaged in agonistic behavior with each other and with bees of other

Table 2. Pollen load analysis of bees collected on Cypripedium reginae flowers
during 2007-2009 after they were observed exiting the flower by the rear orifices.

\begin{tabular}{|c|c|c|c|c|c|}
\hline \multirow[t]{2}{*}{ Insect Taxon } & \multicolumn{3}{|c|}{ Number Caught } & \multirow{2}{*}{$\begin{array}{l}\text { Carry } \\
\text { Pollinia }\end{array}$} & \multirow{2}{*}{$\begin{array}{l}\text { Pollen of } \\
\text { Other Spp. }\end{array}$} \\
\hline & 2007 & 2008 & 2009 & & \\
\hline Anthophora abrupta & 0 & 0 & 1 & 1 & 1 \\
\hline Anthophora terminalis & 0 & 0 & 1 & 1 & 1 \\
\hline Apis mellifera & 0 & 1 & 1 & 2 & 1 \\
\hline Augochlorella persimilis & 0 & 0 & 1 & 0 & 1 \\
\hline Augochlora pura & 6 & 7 & 15 & $4^{*}$ & 18 \\
\hline Augochlorella aurata & 1 & 0 & 2 & $1 *$ & 1 \\
\hline Bombus griseocollis & 0 & 1 & 2 & 0 & 3 \\
\hline Bombus pensylvanicus & 0 & 1 & 0 & 0 & 1 \\
\hline Ceratina calcarata/dupla & 0 & 4 & 1 & 1 * & 3 \\
\hline Ceratina strenua & 1 & 0 & 1 & 0 & 2 \\
\hline Eucera rosae & 1 & 0 & 0 & 0 & 1 \\
\hline Hoplitis spoiliata & 0 & 0 & 1 & 1 & 0 \\
\hline Lasioglossum spp. & 1 & 1 & 0 & 0 & 2 \\
\hline Lasioglossum zophops & 1 & 0 & 0 & 0 & 2 \\
\hline Megachile montivaga & 1 & 0 & 0 & 1 & 1 \\
\hline Osmia distincta & 0 & 0 & 1 & 0 & 1 \\
\hline Grand Totals & 12 & 15 & 27 & $6-12$ & 39 \\
\hline
\end{tabular}




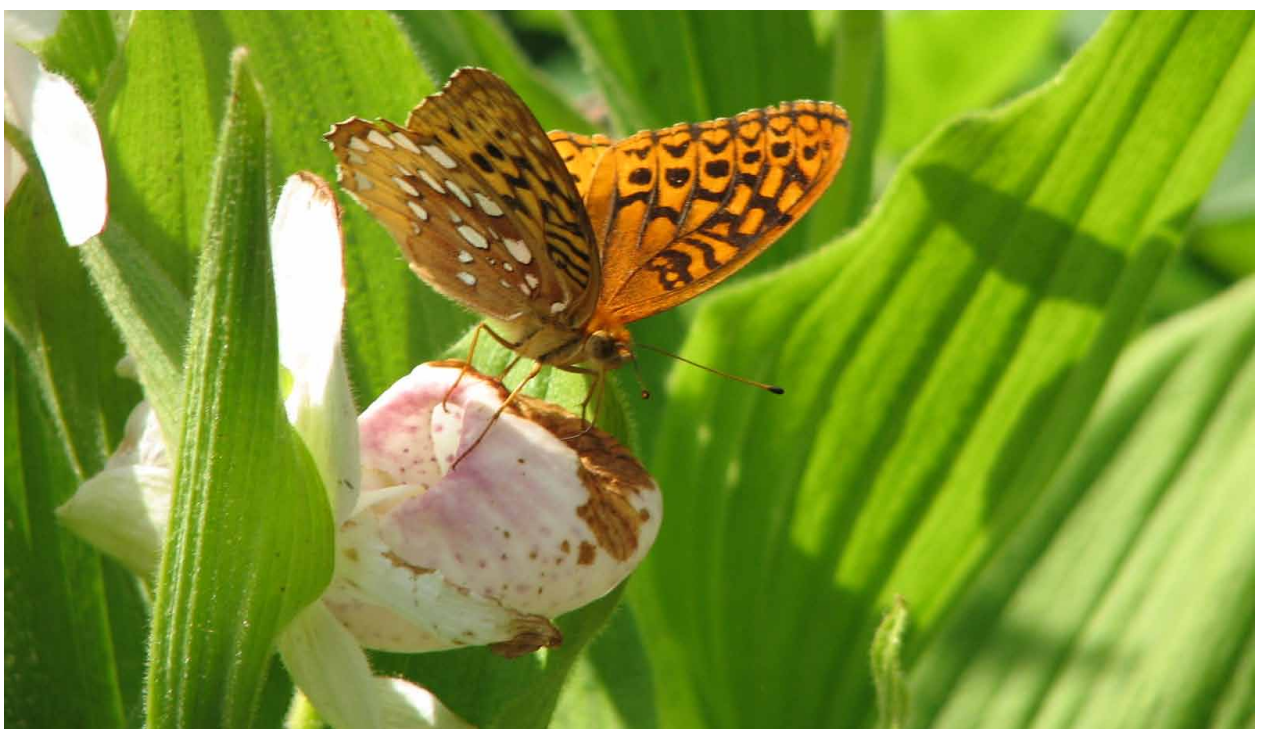

Fig. 2. Great Spangled Fritillary probes brown spots on wilted flower of Cypripedium reginae.
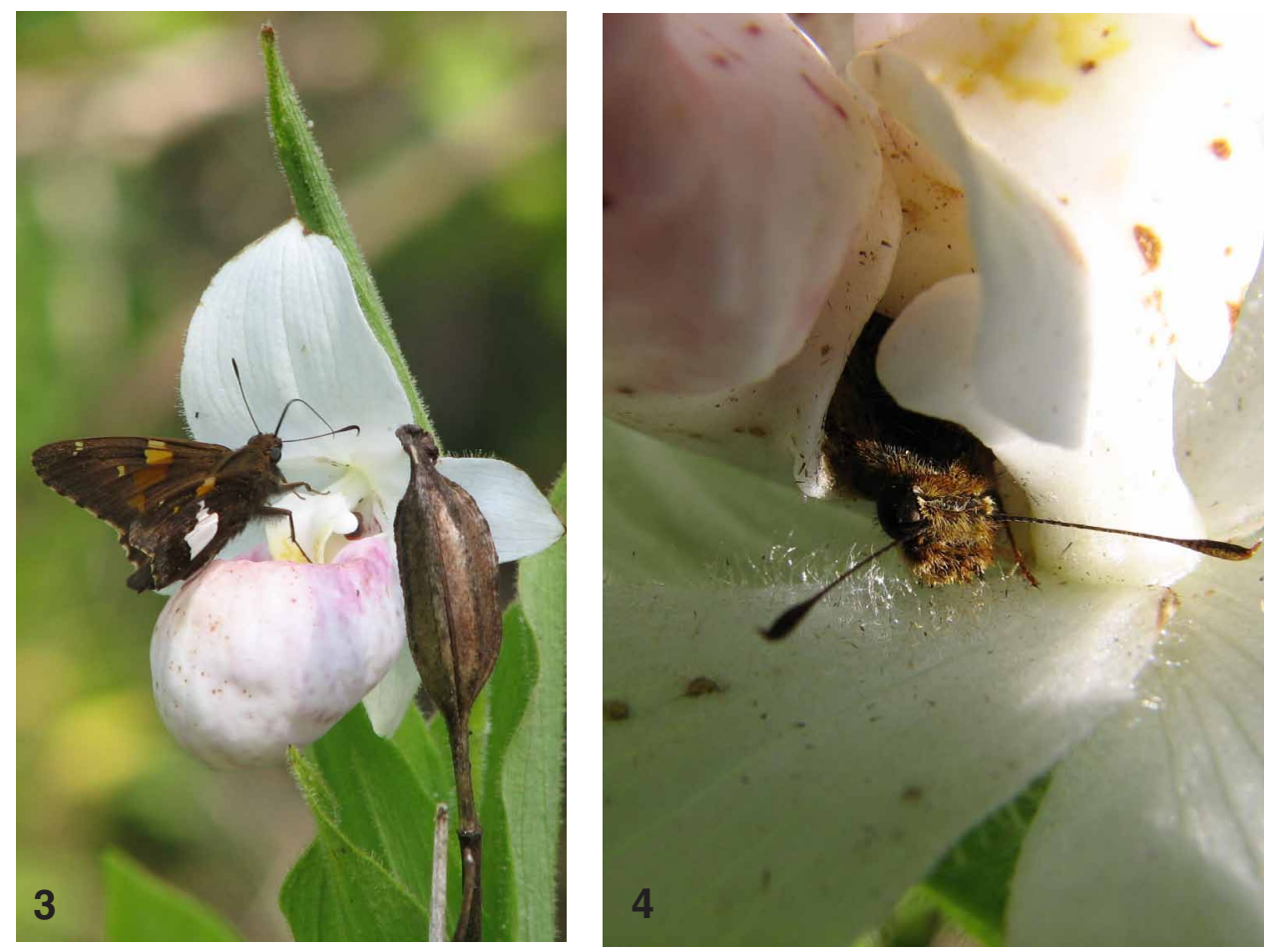

Fig. 3. Unidentified skipper probes dorsal sepal with its extended proboscis. Fig. 4. Dead Polites sp. with head protruding from rear orifice. 
species. Four specimens were collected after they were observed entering the labellum through the large dorsal opening. Once inside, the Bombus sp. rolled around inside the labellum before exiting via the same opening through which it entered. Four specimens collected (Table 1) in 2008 and 2009 attempted to exit the labellum via the rear of the labellum but they were always unable to leave via the much smaller rear orifices. It is possible that their heads could have contacted the dehiscent anthers as they pushed against the rear part of the labellum, so we collected and euthanased them for pollen load analyses. However, the white pollen grains caking the frons, antennae and the rims of their compound eyes belonged to co-blooming Physocarps opulifolius (Rosaceae) and/or Salvia lyrata (Lamiaceae).

In 2007 we found four bees (three specimens of Augochlora pura and one Lasioglossum zophops) dead in the labella of four flowers. While all four carried the pollen of coblooming plants, none carried pollen of $C$. reginae. All remaining bees captured from 2007-2009 were captured after they were observed exiting a flower via one of the rear orifices. The way in which they entered the flower via the broad dorsal entrance varied. Some flew directly into the dorsal opening, landing on the bottom of the interior surface of the labellum. Others landed on the outer surface of the labellum before entering the labellum. No bees were observed landing on the staminode over the three-season period. In either entry method, the weight of the bee often caused the flower to nod on its pedicel. All bees observed crawled towards the rear of the flower along the purplespotted pathway found on the interior surface of the labellum (Fig. 1). Once the bee passed under the stigma it was lost from view. However, several bees slipped backwards more than once and had to repeat their movements. All bees entered the labellum and exited via the rear orifices within 60 seconds or less. Some bees, not caught at this point of re-emergence, launched themselves into the air and appeared to leave the site. Other bees paused on the surface of a lateral petal or crawled onto a leaf and then groomed themselves before flying away.

Excluding the Bombus spp., we collected a total of 54 bees as they exited the flowers over a three-season period. They represented 14 taxa (Table 2). A total of 53 bees carried the pollen of one or more identifiable, co-blooming angiosperms (Table 2) including Physcocarpos sp., Salvia lyrata (see above), Coreopsis lanceolata (Asteraceae) and Zizia aurea (Apiaceae). Specimens of Augochlora pura (Halictidae) and the naturalised Apis mellifera (Apidae) carried the pollen of up to five different flowering plants including a large polyporate grain and a small tricolporate one that could not be matched to the standing co-blooming flora.

Table 3. Bee measurements and Wilcoxon comparisons

\begin{tabular}{|c|c|c|c|c|c|c|c|}
\hline \multirow[t]{2}{*}{ Measure } & \multirow{2}{*}{$\begin{array}{l}\text { Pollinia Vectors } \\
(n=6) \\
\text { Mean } \pm \text { SD }\end{array}$} & \multirow{2}{*}{$\begin{array}{l}\text { Non-Vectors } \\
\text { (excld. Bombus) } \\
(\mathrm{n}=58) \\
\text { Mean } \pm \text { SD }\end{array}$} & \multirow{2}{*}{ 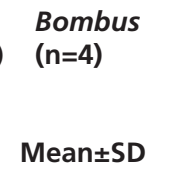 } & \multicolumn{4}{|c|}{$\begin{array}{l}\text { Wilcoxon Comparisons of } \\
\text { Pollinia Vectors vs. Non-Vectors } \\
\text { (excld. Bombus) Bombus }\end{array}$} \\
\hline & & & & W & $\mathbf{P}$ & $\mathbf{W}$ & $\mathbf{P}$ \\
\hline Length (mm) & $10.87 \pm 0.71$ & $7.87 \pm 1.94$ & $20.62 \pm 1.62$ & 21 & $<0.001$ & 24 & 0.010 \\
\hline Width (mm) & $4.44 \pm 0.88$ & $2.66 \pm 0.87$ & $9.06 \pm 0.54$ & 25 & $<0.001$ & 24 & 0.010 \\
\hline Depth (mm) & $3.41 \pm 0.88$ & $2.16 \pm 0.74$ & $6.25 \pm 2.73$ & 57 & 0.007 & 19 & 0.171 \\
\hline
\end{tabular}


Despite the diversity of bees leaving the flower via the rear orifices where they could contact dehiscent anthers, only six specimens (Table 2, Figs 5 \& 6), representing five species, in the long-tongue families Apidae (Anthophora abrupta, A. terminalis, Apis mellifera) and Megachilidae (Hoplitis spoliata, Megachile montivaga) carried discrete segments of the massulate pollinia of $C$. reginae (Figs $5 \& 6$ ). In all cases these pollinia fragments were restricted to the dorsum of their thoraces. Loose, individual grains of $C$. reginae pollen were found on a few specimens of members of the Halictidae (Augochlorella persimilis, A. pura and Augochlorella aurata) and one member of the Apidae (Ceratina calcarata/dupla) but there were less than five isolated and individual grains/slide. We note that Apis mellifera is an introduced species in North America and suspect that this bee species carried the pollinia of $C$. reginae because its physical dimensions were so similar to those of the native species that carried pollinia (Table 3 ). We found that the length and width of Bombus spp. are not the same as the length and width of the six bees carrying pollinia. We also discovered that the length, width and depth of all the remaining bees are not equal to the same variables of the six bees carrying pollinia (Table 3).

Wilcoxon comparisons revealed that bees carrying pollen were significantly larger in all three dimensions than those not carrying pollen when Bombus spp. were excluded from the analysis (Table 3). Bees carrying pollen were also found to be significantly smaller (in length and width, but not depth) than the Bombus spp. visitors (Table 3).

\section{Discussion}

Fecundity vs. Pollinator Diversity/Fidelity. Cypripedium reginae is a rhizomatous species (Luer 1975). Secondary stems in our population showed no obvious relationship between the height and leaf number, and the number of terminal flowers produced. Herring (2007) counted the number of flowers $(n=45)$ and fruits $(n=10)$ in 2006, yielding a conversion ratio of 0.222 . We followed with conversion ratios of 0.046 in 2008 and 0.23 in 2009. These low but variable conversion ratios are typical of other Cypripedium spp. (e.g., C. acaule, C. tibeticum, some populations of C. parviflorum) regardless of primary pollinator or phytogeography (Bernhardt \& Edens-Meier 2010). Cypripedium reginae then follows the predictable pattern of low fertility in most
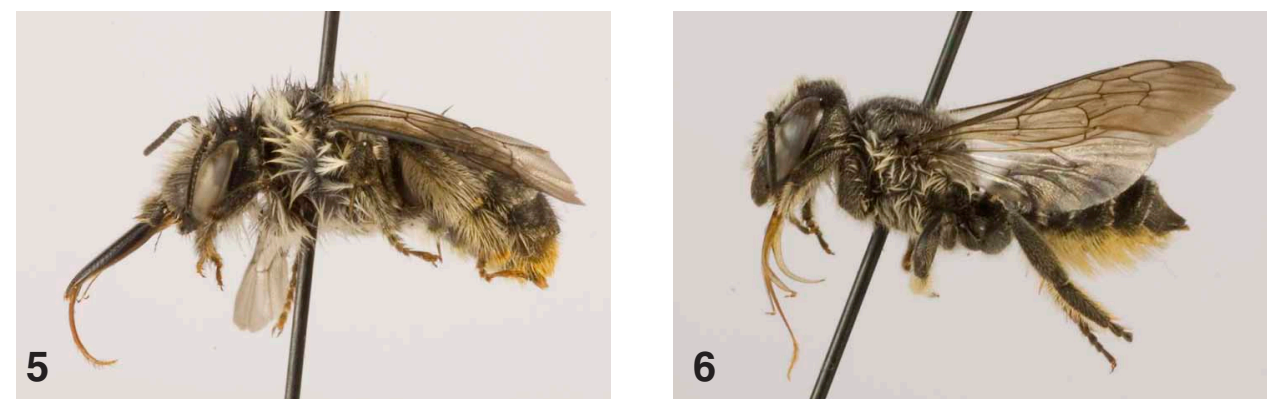

Fig. 5. Anthophora terminalis (2009) (pollina removed).

Fig. 6. Megachile montivaga (2007) from Cypripedium reginae (pollinia removed). 
orchids that do not offer edible rewards (Tremblay et al. 2005). What was unanticipated was the surprisingly high diversity of floral visitors. Our Missouri population received far more visitors than those recorded previously on populations distributed through the eastern half of North America (van der Cingel 2001). However, despite the wide range of visitors, no more than five species could be classified as pollinia vectors. As we were unable to note which bees contacted the stigmas of these flowers, we can only presume that a discrete number of native apids and megachilids are the true pollinators of this orchid in southern Missouri. In addition, this may now include the naturalised A. mellifera. This is not the first time this Afro-Eurasian bee species has been implicated in the pollination of an orchid where it has become naturalised. For example, Coleman (1933) identified A. mellifera as a probable pollinator of Spiranthes sinensis in eastern Australia but $S$. sinensis is a nectar-secreting species dependant on pollinators with prescribed proboscis lengths. In contrast, larger apids and megachilids are the dominant pollinia vectors of $C$. reginae because they share similar physical dimensions reflecting an optimal size for pollinators in the flower of this orchid species.

The Importance of Optimal Size. A recurrent observation in the study of the pollination of Cypripedium spp. is the putative "goodness of fit" between the floral architecture and the pollinia vector. This was first documented in studies of Cypripedium pollination in China (Banziger et al. 2005, 2009; Li et al. 2006, 2008). Flowers with large labella are pollinated by large insects (e.g. Bombus gynes). Species with smaller labella are pollinated by insects with considerably smaller physical dimensions (e.g. Lasioglossum spp., Andrena spp., micro-dipterans; see Bernhardt \& Edens-Meier 2010). Cypripedium reginae has the third largest labellum in North America after C. acaule and C. irupeanum (see Luer 1975). As Cypripedium acaule is pollinated exclusively by large, Bombus gynes (Bernhardt \& Edens-Meier 2010) it should not be surprising that the only pollinia vectors of $C$. reginae in our population were mid-sized bees in the families Apidae and Megachilidae. There appears to be a physical relationship between the dimensions of the exit orifices of the flower and the depth and width of the mid-sized bees that were captured exiting the flower and carrying the pollinia of this orchid. The exit length and width of the orchid measured $6.53 \mathrm{~mm}$ and $3.41 \mathrm{~mm}$ respectively, with a respective standard deviation of 1.46 and 0.97 . Medium-sized bees carrying C. reginae pollinia had a mean width of $4.44 \mathrm{~mm}$ and depth of $3.41 \mathrm{~mm}$ (both measurements with a standard deviation of 0.88 ). The Wilcoxon contrasts (Table 3 ) appear to corroborate this hypothesis as bees with pollen were significantly larger than those without, while still being smaller than the largest Bombus individuals. As our measurements did not include the additional obstructions made by each bee's six limbs it appears that, in order for bees to serve as pollen vectors for these flowers, the insects need to be just a "bit" larger than the exit openings, forcing the bees to squeeze through the orifices on their way out of the orchid. Their struggle to exit the labellum must be tight enough for the dorsum of the thorax to contact the dehiscent anther. The "hairiness" of these medium-sized bees could also be a determining factor in how successfully pollinia adhere to the bee's body as hairs should increase friction between the exit hole and the bee's body. The width and depth of pollinia-vector bees closely matches the exit orifice of the orchid in contrast to the smaller bees' average width and depth dimensions of $2.66 \mathrm{~mm}$ and $2.16 \mathrm{~mm}$ (SD 0.87 and 0.74 ) respectively. Bees with such measurements left the flower without struggling and either failed to contact the anthers or, if they did, carried few pollen grains of the host flower. Bumblebee gynes with a mean length of $20.62 \mathrm{~mm}$ and a width of $9.06 \mathrm{~mm}$ were observed entering the labellum through the large dorsal entrance with a mean length of only $11.96 \mathrm{~mm}$, width of $16.19 \mathrm{~mm}$, and 
depth of $24.98 \mathrm{~mm}$. These 'cozy' flower parameters provide just enough room to roll around a bit. However, exiting via the rear orifices is impossible for these large bees.

Why Do Insects Visit Cypripedium reginae? Although C. reginae flowers offer no obvious food rewards in the form of pollen or nectar, it is by far the largest flower in the habitat and is even physically larger than the head inflorescences of co-blooming Asteraceae. It is a boldly dichromatic flower outside and in. We presume that the spotted patterns inside the labellum function as guides leading the insects to the rear orifices. Constituents in the faint floral fragrances described above were identified as methyl salicylate and benzoic acid methyl ester (Barkman et al. 1997). Interestingly, neither compound was found in any of the other eight Cypripedium spp. analysed in the same study. Methyl salicylate has been found to act as an herbivore-induced plant volatile to recruit specific beneficial insects (James \& Price 2004) as well as serving in plant disease resistance (Shulaev et al. 1997).

Reasons for insect visitations to C. reginae vary. Flies and beetles in the genus Diabrotica may simply land in or on the flowers by chance. Trichiotinus scarabs are flower beetles that may attempt to eat floral tissues. Skippers appear to be drinking, as they extend their proboscis into the interior of the labella following a rain shower. Speyeria cybele could be consuming molecules released by senescent tissues as has been documented in other butterflies in other families, a process known as pharmacophagy (Boppre 1990). Small to medium sized bees must be looking for pollen or nectar but does this also apply to Bombus gynes? Further investigations are needed but Edens-Meier postulates here that, based on previous experimental studies, these large bees may be collecting aromatic compounds for unknown purposes (Schiestl \& Roubik 2003) when they roll in the labellum. Currently scent collection within the family Apidae is best documented in the genus Euglossa and its allies (see Ramirez et al. 2010).

Comparative pollination ecology of $C$. reginae vs. other Cypripedium spp. As in all Cypripedium spp., studied so far, the floral dimensions of $C$. reginae produce a bilaterally symmetrical kettle trap (sensu Banziger et al. 2005) that ensures pollinia dispersal but, as in all Cypripedium spp. it is discretely selective because only insects with parallel physical dimensions can carry pollinia upon escaping from the rear orifices of the flower. The labellum of $C$. reginae received far more visits from non-pollinators over a three-season period than true pollinia-vectors. In this respect, the pollination ecology of C. reginae parallels that of C. plectrochilum (Li et al. 2008) and C. guttatum (Banzinger et al. 2005) which are also visited repeatedly by a broader spectrum of pollinators and non-pollinating but anthophilous insects that are not of optimal size. In C. yunnanense and C. flavum most visitors to these orchids were true pollinia vectors although two Calliphora spp. fell into the labellum and died (Banzinger et al. 2008). Otherwise, most Cypripedium spp. studied so far attract relatively few insects except for pollinators of optimal size ( $\mathrm{Li}$ et al. 2006; Liu et al. 2008, and see review in Bernhardt \& Edens-Meier 2010). This means fewer visits to each flower but it also avoids the consequences of inappropriate visitors destroying flower parts, covering exit orifices when they die in the labellum or accumulating orchid pollen that will never be spread to a second flower (Banziger et al. 2005). We postulate that the comparatively large size, vivid colours and atypical scent of this flower acts as a supernormal stimulus (sensu Manning 1967) on a range of inappropriate but anthophilous insects. Therefore, the architectural dimensions in this species are, once again, the only factors regulating pollinia dispersal as in small-flowered, C. plectrochilum (Li et al. 2008). While the 
suite of floral attractants (physical size, colour and odour) in C. reginae entices diverse visitors into its labellum, floral dimensions select and restrict the final pollinator vector spectrum (sensu van der Pijl \& Dodson 1966).

\section{Acknowledgments}

We are grateful to the Missouri Department of Conservation for showing us the location of the initial population and for providing us with permits. Larry Meier is thanked for his assistance in this project. We are most grateful to Dr. George Yatskievych (MO) for identifying co-blooming flora and photographing pinned bee specimens. We also thank Tamra Raven for her valuable help in locating the second population of Cypripedium reginae. Finally, Dr. Peter Bernhardt wishes to acknowledge the positive influence of the late Surrey Jacobs, a man who could see a humorous side to evolution, for past discussions on floral symmetry and pollination systems. He always made Dr. Bernhardt feel welcomed, comfortable, and accepted.

\section{References}

Barkman TJ, Beaman JH \& Gage DA (1997) Floral fragrance variation in Cypripedium: Implications for evolutionary and ecological studies. Phytochemistry 5: 875-882.

Banzinger J, Sun H \& Luo YB (2005) Pollination of a slippery lady slipper orchid in south-west China: Cypripedium guttatum (Orchidaceae). Botanical Journal of the Linnean Society 148: 251-264.

Banzinger H, Sun H \& Luo YB (2008) Pollination of slippery lady slipper orchid in south-west China; Cypripedium guttatum (Orchidaceae). Botanical Journal of the Linnean Society 148: 251-264.

Bernhardt P \& Dafni A (2000) Breeding system and pollination biology of Mandragora officinarum L. (Solanaceae) in northern Israel. Pages 215-224 in Totland O (ed.) The Scandinavian Association for Pollination Ecology honours Knut Faegri. Norske VidenskapsAkademi matematiske-naturvidenskapelig klasse Serie 39. (Oslo, Norway)

Bernhardt P \& Edens-Meier R (2010) What we think we know vs. what we need to know about orchid pollination and conservation: Cypripedium L. as a model lineage. Botanical Review 76: 204-219.

Boppre M (1990) Lepidoptera and purrolizidine alkaloids: exemplication of complexity in chemical ecology. Journal of Chemical Ecology 16:165-185.

Coleman E (1933) Further notes on the pollination of Spiranthes sinensis (Pers.) Ames. Victorian Naturalist 50: 61-64.

Cribb P (1999) Cypripedioideae. Pp. 105-164 in Pridgeon, Cribb PJ, Chase MW \& Rasmussen FN (eds) Genera Orchidacearum Volume1 1. (Oxford University Press, United Kingdom)

Dafni A \& Bernhardt P (1990) Pollination of terrestrial orchid of southern Australia and the Mediterranean region: systematic, ecological and evolutionary implications. Pp. 193-252 in Hecht MK, Wallace B \& Macintyre RJ (eds) Evolutionary Biology, vol. 24. (Plenum Press: New York)

Edens-Meier R, Vance N, Luo YB, Li P, Westhus E \& Bernhardt P (2010) Pollen-pistil interactions in North American and Chinese Cypripedium L. (Orchidaceae). International Journal of Plant Sciences 171(4). 370-381.

Ferguson CS \& Donham K (1999) Pollinator of clustered lady's slipper Cypripedium fasciculatum (Orchidaceae) in Oregon. North American Native Orchid Journal 5: 180-183.

Herring T (2007) A study of the reproductive systems of selected North American and Chinese Cypripedium species (Orchidaceae). (Unpublished Dissertation Thesis, Saint Louis University) 
James DG \& Price TS (2004) Field-testing of methyl salicylate for recruitment and retention of beneficial insects in grapes and hops. Journal of Chemical Ecology 30: 1613-1628.

Kull T (2008) Fruit-set and recruitment in populations of Cypripedium calceolus L. in Estonia. Botanical Journal of the Linnean Society 126: 27-38.

Li P, Luo YB, Bernhardt P, Yang XQ, Kay, Y (2006) Deceptive pollination of the lady's slipper Cypripedium tibeticum (Orchidaceae). Plant Systematics and Evolution 262: 53-63.

Li P, Luo Y, Bernhardt P, Kou Y, Pernher H (2008) Pollination of Cypripedium plectrochilum (Orchidaceae) by Lasioglossum spp. (Halictide), the roles of generalist attractants versus restrictive floral architecture. Plant Biology 10: 220-230.

Liu S J, Chen LiJ, Rao WH, Li LQ, Zhang YT (2008) Correlation between numeric dynamics and reproductive behaviour in Cypripedium lentiginosum. Acta Ecologica Sinica 28: 111-121.

Luer CA (1975) The Native Orchids of the United States and Canada; excluding Florida. (The New York Botanical Garden, Bronx, New York, U.S.A.)

Manning A (1967) An Introduction to Animal Behavior. (Addison-Wesley Publishing Co. Reading, Massachusetts, U.S.A.)

R Development Core Team (2010) R: A language and environment for statistical computing. R Foundation for Statistical Computing. Vienna, Austria. (http://www.R-project.org)

Ramirez S, Eltz T, Fritzsch F, Pemberton R, Pringle E, \& Tsutsui N (2010) Intraspecific geographic variation of fragrances acquired by orchid bees in native and introduced populations. Journal of Chemical Ecology 36: 873-884.

Schiestl FP \& Roubik DW (2003) Odor compound detection in male Euglossine bees. Journal of Chemical Ecology 29: 253-257.

Shulaev V, Silverman P, \& Raskin I (1997) Airborne signaling by methyl salicylate in plant pathogen resistance. Nature 385: 718-721.

Sokal RR \& Rohlf FJ (1995) Biometry, third edition. (W. H. Freeman and Company, New York, New York): 427-430.

Stoutamire WP (1967) Flower biology of the lady's slippers (Orchidaceae: Cypripedium). Michigan Botanist 6: 159-175.

Tremblay RL, Ackrman JD, Zimmerman JK \& Clavo C (2005) Variation in sexual reproduction in orchids and its evolutionary consequences: a spasmodic journey to diversification. Biological Journal of the Linnean Society: 84: 1-54.

Van der Cingel NA (2001) An Atlas of Orchid Pollination: Orchids of America, Africa and Australia. (A.A. Balkema, Rotterdam Holland)

Van der Pijl L \& Dodson CH (1966) Orchid Flowers: their Pollination and Evolution. (University of Miami Press. Miami, Florida, U.S.A.)

Vogt CA (1990) Pollination in Cypripedium reginae (Orchidaceae). Lindleyana 5: 145-150.

Zheng GL, Li P, Tai Y, An D, Kou Y, \& Luo Y ( in press) Flowering and fruit set dynamics in Cypripedium. Acta Ecologica Sinica. 